\title{
Resolución alternativa de conflictos ante el Servicio Nacional del Consumidor (SERNAC)*
}

\author{
Methods of Alternative Dispute Resolution regarding the SERNAC
}

Maria Elisa Morales ${ }^{\text {a }}$

Universidad Austral de Chile, Chile

DOI: https://doi.org/10.11144/Javeriana.vj69.racs

maria.morales@uach.cl

ORCID: https://orcid.org/0000-0003-1200-7253

Recibido: 02 Octubre 2019

Nathalie Walker

Aceptado: 15 Octubre 2019

Universidad Andrés Bello, Chile

ORCID: https://orcid.org/0000-0001-5518-3578

\section{Resumen:}

Este trabajo busca analizar las denominadas mediaciones individuales y colectivas como mecanismos alternativos de resolución de conflictos operados por el Servicio Nacional del Consumidor (SERNAC). Para ello, se revisa y comenta el texto de la Ley 19.496 (Ley de Protección de los Derechos de los Consumidores), antes y después de su última modificación, con una técnica de contraste. El estudio de la normativa y sus cambios concluye que las "mediaciones" individuales y colectivas no son, en rigor, mediaciones, sino procedimientos que representan un esfuerzo legislativo encaminado a establecer pautas de regulación para ese tipo de Alternative Dispute Resolution (ADR).

Palabras clave: consumidor, resolución alternativa de conflictos, ley de protección al consumidor.

Abstract:

This paper analyzes the individual and collective mediations as alternative dispute resolution schemes (ADRs) developed by SERNAC (Servicio Nacional del Consumidor). In order to reach this objective, this work examines and comments on the consumer protection law, before and after its last modification, with a contrast' technique. The study of the normative and its changes leads us to the general conclusion about the individual and collective mediation are, strictly speaking, negotiations. These negotiations represent a legislative effort directed to introduce rules for these types of Alternative Dispute Resolution (ADR).

Keywords: consumer, alternative dispute resolution, consumer protection law.

\section{Introducción}

En un sentido amplio, la resolución alternativa de conflictos (ADR por sus siglas en inglés) o esquemas de resolución alternativa de conflictos (ADRs por sus siglas en inglés), consisten en métodos estructurados para resolver disputas diferentes del procedimiento judicial ${ }^{1}$. Estos métodos intentan superar las deficiencias propias de la litigación ante los tribunales de justicia, frecuentemente considerada como demasiado cara y lenta ${ }^{2}$. Se entienden incluidos dentro de los ADR el arbitraje, la mediación y la negociación ${ }^{3}$, entre otros. En el ámbito del Derecho del Consumo, los ADR cobran cada vez más relevancia y son vistos como una forma menos costosa de aplicación y cumplimiento de la norma ${ }^{4}$.

En el Derecho del Consumo chileno se han señalado por lo menos tres formas de resolución alternativa de conflictos. Éstas son: la denominada "mediación individual", la "mediación colectiva" y el sistema de resolución alternativa de conflictos aplicable en el caso de otorgamiento del "Sello SERNAC" . Como consecuencia de la ineficacia del Sello del Servicio Nacional del Consumidor (en adelante SERNAC), este último no ha operado, razón por la que solo abordaremos los dos primeros.

Notas de autor

\footnotetext{
a Autora de correspondencia. Correo electrónico: maria.morales@uach.cl
} 
Con el ánimo de contextualizar, partiremos refiriéndonos brevemente a los ADR en el Derecho comparado para luego entrar en el caso chileno con un análisis genérico y crítico de la denominada "mediación ante el SERNAC". A continuación, abordaremos y describiremos brevemente el procedimiento de "mediación individual". Gran parte del trabajo se dedicará al estudio de los procedimientos de "mediación colectiva", hoy en día denominado "procedimiento voluntario para la protección del interés colectivo o difuso de los consumidores", donde concluiremos explicando las ventajas de este último.

Para situarnos en los distintos escenarios de la reforma a la Ley 19.496, nos referiremos al texto antes de la reforma, al texto aprobado por el Congreso Nacional, al texto después del control preventivo realizado por el Tribunal Constitucional y al texto promulgado. Nuestro trabajo finaliza con una reflexión acerca del intento de institucionalizar la conciliación en el ámbito del procedimiento sancionatorio.

\section{Referencia a los ADR en el Derecho del Consumo Comparado}

Se dice que los sistemas escandinavos han estado a la vanguardia en materia de ADR y, más específicamente, en la resolución de conflictos entre consumidores y proveedores, con la figura del Consumer Ombudsman ${ }^{6}$. También se afirma que los países con sistemas de derecho anglosajón han sido los primeros en desarrollar técnicas de mediación desde 1970, a través de los Community Justice Centres ${ }^{7}$. Sin embargo, en los países con sistemas de derecho continental, el reconocimiento de los ADR como una forma de resolver conflictos entre consumidores y proveedores se ha producido de manera más generalizada, en forma más o menos reciente.

En el 2007, el Comité para Políticas de Consumo (CCP) de La Organización para la Cooperación y el Desarrollo Económicos (OCDE) publicó un documento denominado "Recomendación de la OCDE sobre resolución de disputas y resarcimiento a consumidores" ${ }^{8}$. En dicho documento se da cuenta de la necesidad de que los Estados miembros cuenten con mecanismos efectivos para la solución de controversias, que sean fáciles de usar, oportunos, efectivos, sin costos o cargas innecesarias, y que respondan a las variadas naturalezas y características de las quejas de los consumidores. En mérito de lo anterior, se recomendó la adopción de ADRs para resolver sus disputas individuales y colectivas con los proveedores.

Lo anterior es actualmente una tendencia en el derecho extranjero. De hecho, los mecanismos alternativos de resolución de conflictos son cada vez más vistos como un medio para proporcionar una aplicación eficaz y eficiente del derecho del consumo. Así se puede verificar si se revisan algunos trabajos de Derecho comparado.

En efecto, según el reporte general ${ }^{9}$ presentado en el último congreso temático de la Academia Internacional de Derecho Comparado ${ }^{10}$, existen distintos modelos que los ordenamientos jurídicos han venido implementando para resolver extrajudicialmente las disputas entre consumidores y proveedores. Así, en muchos casos, es la agencia estatal la que provee de mecanismos alternativos de resolución de conflictos de los consumidores, por ejemplo, a través de negociaciones directas con el proveedor en respuesta a un reclamo del consumidor, o mediante soluciones algo más formales a través de mecanismos de mediación, conciliación o arbitraje. En otros casos, son otros organismos los que están legalmente llamados a proporcionar procesos extrajudiciales de solución de controversias, ya sea para reclamos de los consumidores en general, o en sectores específicos del mercado, como, por ejemplo, las asociaciones de consumidores o de proveedores.

En la Unión Europea se adoptó un esquema común para la resolución alternativa de disputas a través de la Directiva 2013/11, en la que los Estados miembros tienen la obligación de proporcionar mecanismos de resolución alternativa de conflictos al consumidor. La estructura precisa de estos servicios depende de cada Estado. En cualquier caso, deben designar organismos acreditados a cargo, ya sean públicos o privados, y garantizar que sus procedimientos sean transparentes, justos y eficaces.

Las ventajas de estos mecanismos son bastante reconocidas. La misma Directiva 2013/11, en su preámbulo, designa a los ADR como "una solución extrajudicial sencilla, rápida y asequible para los litigios entre los consumidores y los comerciantes" 11 . Se agrega que estos esquemas ofrecen a las partes la oportunidad de 
que todos obtengan beneficios ${ }^{12}$ : el consumidor, por un lado, el respeto de su derecho y posiblemente una indemnización, y el proveedor gana la confianza del consumidor. Además, se dice que estos mecanismos mejoran el acceso a la justicia, si se piensa que hacen viable la resolución de conflictos que, de otra manera, llegarían a un tribunal ${ }^{13}$.

Con todo, es posible identificar algunas desventajas al emplear los $\mathrm{ADR}^{14}$. En primer lugar, su naturaleza voluntaria, que deja espacio para que cierto tipo de proveedores evadan el procedimiento. Por otro lado, la aplicación del derecho del consumo fuera de los tribunales podría traer problemas de incertidumbre y de interpretación del derecho aplicable y, dada la baja cuantía que ostentan los asuntos individuales en esta materia en general, no pareciera ser una decisión racional someter la decisión surgida de un ADR a la revisión judicial.

Para evitar este tipo de desventajas y propender a que los ADR sean una herramienta que contribuya y refuerce la protección de los derechos de los consumidores, se requiere de una regulación cuidadosa y clara, que, como veremos, no es el caso del sistema chileno.

\section{Sobre la denominada “mediación” ante el SERNAC}

Es frecuente el empleo de la nomenclatura "mediación” tanto para referirse a la práctica que — de facto- ha venido realizando el SERNAC hasta hoy, como para los nuevos procedimientos que se intentaron incorporar por el Proyecto de Ley que modifica la Ley 19.496, Boletín n. ${ }^{\circ} 9.369-03^{15}$, proyecto que se transformó en la Ley 21.081 del 13 de septiembre de 2018. Sobre el punto, es preciso destacar que ninguno de esos procedimientos constituye propiamente una mediación. La principal razón para afirmar lo anterior es que el SERNAC no es un tercero imparcial y neutral.

Es claro que, aunque no hay consenso en la terminología de los $\mathrm{ADR}$, en la mediación es crucial la presencia de un tercero ajeno a la disputa que acerca a dos o más partes para alcanzar un acuerdo ${ }^{16}$.

La característica de la imparcialidad apunta a que el mediador no puede actuar en prejuicio o interés de una de las partes, ni valorará la actitud de ninguna de ellas en el conflicto. Así, el mediador debe tratar el conflicto planteado de manera que su única motivación sea la de detectar los intereses y necesidades de las partes, para que éstas sean capaces de generar alternativas ${ }^{17}$.

La neutralidad está estrechamente relacionada con la imparcialidad, y constituye una de las principales características de la mediación. Supone

el respeto del mediador respecto de los puntos de vista planteados por las partes implicadas en el conflicto, así como del resultado de la mediación, no inclinándose en su actuación por ninguna de las alternativas que planteen. Para ello, en ningún momento impondrá criterios propios, siendo su labor la de ayudar a las partes en la búsqueda y formulación de alternativas de una forma activa y a través de unas técnicas que componen la metodología de la mediación ${ }^{18}$.

Hasta ahora, el SERNAC se ha venido auto confiriendo la facultad de realizar esta suerte de "mediaciones individuales" en base a lo dispuesto por el artículo 58 letra f) de la Ley 19.496 o Ley de Protección de los Derechos de los Consumidores (LPDC de ahora en adelante), norma que le permitía "promover un entendimiento voluntario entre las partes". De la misma forma, se ha llamado "mediaciones colectivas" a cierta actividad no regulada en la LPDC entre el SERNAC y un proveedor considerado infractor, fundándose el órgano administrativo en su facultad más amplia de velar por la protección de los derechos de los consumidores, la que incluye el resguardo de sus intereses colectivos o difusos ${ }^{19}$.

Como pudo apreciarse en su momento, estas prácticas tenían un débil fundamento legal ${ }^{20}$, habida cuenta de que el SERNAC es un órgano del Estado y que, por lo tanto, no tiene más atribuciones que aquellas que le otorgue la ley. 
Pese a lo expresado, el Proyecto de Ley aprobado por el Congreso Nacional —actual Ley 21.081— insistió en llamar "mediación individual" a los intentos efectuados por el SERNAC para llegar a acuerdos entre consumidores y proveedores ${ }^{21}$. Esto, se diferencia de lo que ocurre en materia de intereses colectivos y difusos en donde el procedimiento fue expresamente denominado "procedimiento voluntario" y no "mediación colectiva", que era la denominación anteriormente dada ${ }^{22}$.

Por nuestra parte, consideramos que, en el marco de los ADR, ambos procedimientos tienen la naturaleza de una negociación ${ }^{23}$. En efecto, la negociación constituye: "un sistema de resolución de conflictos mediante el cual dos o más partes con intereses contrapuestos se comunican para llegar a un acuerdo, cediendo en algo cada una de ellas" ${ }^{24}$. Así, es frecuente que las partes, o al menos una de ellas, intente llegar a un acuerdo antes de acudir a la vía jurisdiccional o arbitral, por lo que suele ser el primer sistema de resolución de conflictos al que aquéllas acuden. Incluso iniciado un proceso judicial o arbitral, es factible que las partes intenten una negociación para resolver de forma más rápida y barata el litigio, utilizando, por ejemplo, mecanismos que permitan la suspensión del proceso ${ }^{25}$.

En la negociación solo intervienen las partes,

aunque es posible la intervención de un tercero al que se solicite una opinión experta sobre algún tema (aunque su opinión no es vinculante) para orientar la resolución del conflicto. También es factible que por las partes negocien sus abogados o apoderados como representantes de aquellas. ${ }^{26}$

Otra forma de negociación es aquella en la que el órgano estatal, que representa los intereses de los consumidores, trata directamente con la empresa o asociación de proveedores ${ }^{27}$.

\section{Mediación individual ante el SERNAC: procedimiento, sujetos, plazos y efectos}

El procedimiento para arribar a un acuerdo individual entre proveedor y consumidor a instancias del SERNAC no está contemplado en la actual Ley 19.496. Por lo mismo, en la práctica, el artículo $58 \mathrm{f}$ ) traduce la función del SERNAC de "recibir reclamos de consumidores que consideren lesionados sus derechos y dar a conocer al proveedor respectivo el motivo de inconformidad a fin de que voluntariamente pueda concurrir y proponer las alternativas de solución que estime convenientes" ${ }^{28}$. Sobre la base de la respuesta del proveedor reclamado, el SERNAC promueve un acuerdo voluntario entre las partes. Dicho procedimiento tiene fijado, vía resolución interna ${ }^{29}$, un plazo de duración de 25 días hábiles, sin embargo, el tiempo de duración promedio es de 15 días hábiles ${ }^{30}$.

$\mathrm{Al}$ no establecerse una regulación legal pormenorizada del procedimiento, el SERNAC se ha convertido en una suerte de depositario o "buzón" de los reclamos de los consumidores, sin que aquel tenga un rol muy activo en cuanto fomentar alternativas de solución a los conflictos.

En este procedimiento siempre interviene el consumidor, en tanto se activa con su reclamo individual. Igualmente, la actuación del SERNAC siempre está presente. Sin embargo, la participación del proveedor es eventual ya que es totalmente voluntaria y, al no estar obligado a dar una respuesta, su pasividad o incluso su rechazo no tiene ninguna consecuencia jurídica para él.

En el proyecto aprobado por el Congreso Nacional se contemplaba un párrafo denominado "[d]e la mediación individual, la conciliación y el procedimiento sancionatorio instruido por el Servicio Nacional del Consumidor" ${ }^{31}$, que pretendía, entre otras cosas, regular en su artículo $50 \mathrm{G}$ la denominada mediación individual. Allí no se observa ninguna mención a la actividad que debería desplegar el SERNAC como "tercero imparcial" que daría el impulso inicial a la negociación, ni quiénes, en concreto, asumirían ese rol dentro del SERNAC. Así, se ha opinado que se trataría de un funcionario que actuaría 
como una suerte de mensajero de las propuestas y contrapropuestas que por escrito se hacen las partes. Alguna evidencia muestra que los llamados ejecutivos de atención de público (de ingreso y de gestión) son los encargados de "gestionar" la mediación. Es probable que gran parte de estos funcionarios sean profesionales, pero es probable también que no posean especialización en mediación, aun cuando dadas las condiciones en que se desarrolla esta intervención no parece ser necesario $^{32}$.

Luego del control de constitucionalidad ejercido por el Tribunal Constitucional ${ }^{33}$, el artículo dedicado a la mediación individual fue declarado inconstitucional. Así, la única mención a las mediaciones individuales en el texto resultante es la facultad de realizarlas a solicitud del consumidor, a cargo de las organizaciones para la defensa de los derechos de los consumidores ${ }^{34}$.

En cuanto a los efectos de la llamada mediación individual, en caso de existir respuesta del proveedor reclamado, el SERNAC promueve un entendimiento voluntario entre las partes. Si se arriba a un acuerdo, éste se hace constar en un documento que, según la ley, tiene el carácter de una transacción extrajudicial. En consecuencia, una vez cumplidas sus estipulaciones, extingue la acción del reclamante para perseguir la responsabilidad contravencional del proveedor (art. $58 \mathrm{f}$ ).

\section{Las denominadas "mediaciones colectivas" hoy "procedimiento voluntario para la protección del interés colectivo o difuso de los consumidores”}

Como se señaló, las denominadas mediaciones colectivas ${ }^{35}$ no están reguladas en la ley 19.496 (LPDC), pero se ha interpretado que el servicio se atribuye estos procedimientos en virtud de su facultad más amplia de velar por la protección de los derechos de los consumidores, la que incluye el resguardo de sus intereses colectivos o difusos ${ }^{36}$. Sin perjuicio de lo anterior, el propio SERNAC ha ideado un procedimiento o protocolo de actuación que contempla una serie de etapas ${ }^{37}$.

\section{"Mediaciones colectivas": procedimiento, sujetos, partes y efectos}

El objeto de estas "mediaciones colectivas" es que los proveedores cesen en las acciones que, según el SERNAC, constituyen conductas infractoras. El mismo órgano administrativo las ha definido como un procedimiento voluntario que tiene el propósito de

dar a conocer e informar a los proveedores respecto de situaciones de incumplimiento a la Ley $\mathrm{N}^{\circ} 19.496$, (...), a fin de que éstos realicen los ajustes pertinentes y formulen las propuestas de solución que sean pertinentes (...). Tras la revisión de las referidas propuestas y en aquellos casos en que las mismas se ajusten a la citada Ley $\mathrm{N}^{\circ} 19.496$, el SERNAC las valida, manifestando que la propuesta de que se trate se estima suficiente ${ }^{38}$.

En síntesis, el procedimiento cuenta con siete etapas, que se enumeran a continuación.

La primera, es una etapa previa de toma de conocimiento de una situación potencialmente infractora. Las vías o medios a través de los cuales el SERNAC toma conocimiento de las situaciones consideradas infractoras son tres: las denuncias efectuadas por los consumidores; el análisis de información que los proveedores aportan, previa instancia del SERNAC; o, a través del resultado de acciones efectuadas por el servicio, de acuerdo con su planificación estratégica de intervención de mercados ${ }^{39}$.

La segunda etapa del procedimiento es la denominada "apertura de la mediación", en la que se comunica el inicio mediante un oficio a los consumidores, a la empresa, a los organismos reguladores y fiscalizadores de ésta. Dicho oficio consiste en una comunicación que el servicio envía al proveedor con el fin de alcanzar una solución extrajudicial e integral ante la problemática que, se considera, infringe la normativa de protección al 
consumidor. La idea es que, producto de esta acción, el proveedor realice los ajustes pertinentes y así evite o cese su infracción a los derechos de los consumidores ${ }^{40}$.

La tercera etapa consiste en la aceptación o rechazo de la empresa de participar en el procedimiento. Debido a que es un procedimiento voluntario, la empresa tiene el derecho a no querer participar de él. Si no participa, no existe consecuencia jurídica alguna para dicha conducta. Si decide participar, presentará ante el SERNAC una propuesta de solución que el servicio evaluará para determinar si la solución ofrecida responde de manera integral al problema reclamado. Si acepta la solución ofrecida, se considera una mediación colectiva favorable y la comunicará a los consumidores y a los medios de comunicación. Si, por el contrario, el proveedor no participa o su propuesta es estimada insuficiente, se considera una medicación colectiva desfavorable y se dispone el archivo o se prepara la vía judicial, según sea el caso ${ }^{41}$.

Cuando se trata de mediaciones colectivas favorables puede existir una cuarta etapa de implementación de la solución y, luego de ésta, una quinta etapa de acreditación de cumplimiento. En consecuencia, la empresa deberá demostrar ante el SERNAC que cumplió con la totalidad del acuerdo alcanzado en la negociación a través de una auditoría externa, o con la validación técnica del mismo SERNAC.

En cuanto a las partes, solo intervienen el SERNAC y el proveedor involucrado, para quien el procedimiento es totalmente voluntario. Como la "mediación colectiva” no está regulada legalmente, no está sujeta a un plazo legal. Por la misma razón, no está claro cuáles son sus efectos.

A favor de estas negociaciones informales y desreguladas se apunta la flexibilidad. Sin embargo, dicha virtud no logra superar sus varios inconvenientes. El primero y más grave es que no suspende el plazo de prescripción para ejercer las acciones que la ley dispone a favor de los consumidores. Luego, al tratarse de un procedimiento no establecido en alguna ley o reglamento, genera un problema de incertidumbre para consumidores, proveedores y demás órganos estatales con competencias en materia de protección al consumidor. Esto último puede llegar a generar superposiciones o, incluso, contradicciones entre los órganos de la administración del Estado, al afectar el principio de coordinación. El proyecto y la subsecuente Ley 21.081 han intentado hacerse cargo de parte de estos inconvenientes.

\section{El nuevo "procedimiento voluntario para la protección del interés colectivo o difuso de los consumidores"}

En atención a las modificaciones efectuadas por la Ley 21.081, las comúnmente denominadas "mediaciones colectivas" pasan a denominarse "Procedimiento voluntario para la protección del interés colectivo o difuso de los consumidores". De este modo, se llamó a las cosas por su nombre: "procedimiento voluntario" y no "mediación colectiva” ${ }^{42}$. Quizás, habría sido más propio aún denominarlo "procedimiento voluntario de negociación" pues, como ya se ha tenido oportunidad de reflexionar, la actividad realizada por el SERNAC y que se ha denominado "mediaciones individuales" y "mediaciones colectivas", nunca ha sido ni será una mediación, sino un proceso de negociación.

En efecto, la Ley $21.081^{43}$, a continuación del artículo $54 \mathrm{G}$ ), agrega un nuevo párrafo denominado “[d]el procedimiento voluntario para la protección del interés colectivo o difuso de los consumidores” con 12 artículos $(54 \mathrm{H}$ a S), que provee una regulación legal a los procedimientos conocidos hasta ahora como "mediaciones colectivas".

Con la entrada en vigor de estas modificaciones se vendría a superar uno de los mayores inconvenientes de estos procedimientos: el problema de certeza jurídica. Además, se establece la suspensión del plazo de prescripción de las denuncias y acciones establecidas en la LPDC durante el tiempo que medie entre la notificación al proveedor de la resolución que da inicio al procedimiento y la notificación de la resolución de término. 
Otro asunto que se intenta solucionar es el asunto del plazo del procedimiento. El artículo $54 \mathrm{~J}$ señala que el plazo máximo de duración de este procedimiento voluntario es de tres meses, contado a partir del tercer día de la notificación al proveedor de la resolución que le da inicio. Este plazo es prorrogable por una sola vez, de oficio o a solicitud del proveedor, hasta por tres meses, por resolución fundada en la que se justifique la prórroga por la existencia de una negociación avanzada o por la necesidad de mayor tiempo de revisión de antecedentes o para el análisis de las propuestas formuladas. Este plazo no podrá ser extendido cuando la necesidad de la prórroga se explique por un comportamiento negligente del proveedor involucrado en la negociación.

Si dentro del plazo original o prorrogado no hubiere acuerdo, se entenderá fracasado el procedimiento, circunstancia que será certificada por el SERNAC en la resolución de término.

Dicho plazo, en casos complejos, podría resultar muy breve, considerando que las asociaciones de consumidores y los consumidores potencialmente afectados podrán formular las observaciones que estimen pertinentes y sugerir ajustes a la solución ofrecida (artículo $54 \mathrm{~N}$ ). Sobre este aspecto, Pablo Rodríguez Arias, presidente de la Asociación de Consumidores FOJUCC, ha expresado que:

la práctica judicial (...) ha demostrado que el establecer el daño y reparación frente a un procedimiento colectivo no es una cuestión de semanas o días, sino que puede ser un proceso que requiera tiempo y que, por lo mismo, este plazo de tres meses puede provocar que, con el afán de llegar a término el proceso, no se estudie de manera completa la situación ni se obtenga una reparación íntegra ${ }^{44}$.

Este es uno de los puntos en donde se manifiesta de un modo más notorio que no hay dos partes equilibradas en su poder negociador. Si las hubiera, podrían fijar plazos convencionales para el procedimiento, pero no pueden, precisamente porque el SERNAC no es una parte cualquiera, sino el que fija las pautas y el avance del procedimiento.

Pese a lo expuesto en materia de plazos, el artículo $54 \mathrm{~J}$ no fue objeto de reparos por la sentencia del Tribunal Constitucional que efectúo el control de constitucionalidad del Proyecto de Ley.

Otro vacío que la reforma vendría a llenar es el tema de los efectos del acuerdo. En efecto, según el artículo $50 \mathrm{Q}$, es posible que el acuerdo produzca efecto erga omnes. Recordemos que, si bien este artículo fue declarado conforme a la Constitución por el voto de mayoría del fallo del Tribunal Constitucional ${ }^{45}$, fue, a la vez, considerado una disposición que reviste el carácter de ley orgánica constitucional ${ }^{46}$.

De acuerdo con lo previsto en el artículo 54 Q, para que el acuerdo contenido en la resolución dictada por el SERNAC produzca efecto erga omnes, aquél debería ser aprobado por el juez de letras en lo civil correspondiente al domicilio del proveedor. El tribunal sólo podría rechazar el efecto erga omnes si el acuerdo no cumple con los aspectos mínimos establecidos en el inciso $2 .^{\circ}$ del artículo precedente. Vale decir, si el acuerdo no contemplara:

1. El cese de la conducta que pudiere haber afectado el interés colectivo o difuso de los consumidores ${ }^{47}$.

2. El cálculo de las devoluciones, compensaciones o indemnizaciones respectivas por cada uno de los consumidores afectados, cuando proceda.

3. Una solución que sea proporcional al daño causado, que alcance a todos los consumidores afectados y que esté basada en elementos objetivos.

4. La forma en la que se harán efectivos los términos del acuerdo y el procedimiento por el cual el proveedor efectuará las devoluciones, compensará o indemnizará a los consumidores afectados.

5. Los procedimientos a través de los cuales se cautelará el cumplimiento del acuerdo, a costa del proveedor.

El tribunal fallará de plano y sólo será procedente el recurso de reposición con apelación en subsidio en contra de la resolución que rechace el acuerdo. Aprobado, el acuerdo surtirá los efectos de una transacción 
extrajudicial respecto de todos los consumidores potencialmente afectados, con excepción de aquéllos que hayan hecho valer sus derechos ante los tribunales con anterioridad, hayan suscrito avenimientos o transacciones de carácter individual con el proveedor, o hayan efectuado reserva de sus acciones.

Sobre este punto, causa profunda extrañeza la rigidez contenida en la Ley $21.081^{48}$ y que se manifiesta en el hecho de que el juez deba resolver de plano, pues es la forma menos frecuente de fallar de nuestros jueces. Al respecto, el 16 de agosto de 2017, en su informe al Proyecto de Ley (oficio 129-2017), la Corte Suprema señaló que:

no es una vía prevista ordinariamente por nuestra legislación, limitándose su utilización para casos específicos y sin mayor relevancia, lo que pareciera no corresponder a este caso. En efecto, tratándose de la única intervención del tribunal en estas causas, y considerando el análisis de garantías mínimas que el tribunal debiese efectuar en conformidad con lo señalado en el acápite anterior, las actuaciones del tribunal debieran realizarse, al menos, con conocimiento de las partes, en conformidad con lo señalado en el artículo 69 inciso 2. ${ }^{\circ}$ del Código de Procedimiento Civil; sobre todo, en consideración a los efectos que se siguen de la dictación de esta resolución aprobatoria, como por ejemplo, el inicio del cálculo del plazo para publicar el extracto del acuerdo en los medios que correspondan ${ }^{49}$.

También es viable preguntarse si es o no tan formal o acotada la revisión del acuerdo que hará el juez de letras en lo civil, en los términos que plantea la Ley $21.081^{50}$. Recordemos que se dice que: "El tribunal sólo podrá rechazar el efecto erga omnes si el acuerdo no cumple con los aspectos mínimos establecidos en el inciso $2 .^{\circ}$ del artículo precedente". Lo relevante es que esos aspectos no siempre se refieren a requisitos formales fáciles de analizar, como ocurre, por ejemplo, con la forma en la que se harían efectivos los términos del acuerdo y el procedimiento por el cual el proveedor efectuaría las devoluciones, y compensaría o indemnizaría a los consumidores afectados. Sobre este punto, la LPDC modificada impone un enorme desafío a nuestros jueces civiles, habida cuenta de que, en muchas ocasiones, los acuerdos colectivos requieren de precisiones no solo de carácter jurídico, sino también —o más bien- de carácter económico. Por lo mismo, sería necesario que los jueces estén a la altura del desafío, con la debida capacitación y asesoría para dar soluciones eficaces, a fin de no frustrar las expectativas de los consumidores con un mal arreglo por el desconocimiento de las complejidades asociadas a este tipo de materias.

$\mathrm{Al}$ respecto, en el informe al Proyecto de Ley correspondiente al oficio 129-2017, la Corte Suprema señaló sobre este punto que:

Si bien parece razonable que el tribunal no entre en la calificación de las circunstancias particulares que las partes han acordado, no es menos cierto que los tribunales y las resoluciones que éstos dicten, no pueden avalar conductas que vulneren las garantías mínimas establecidas por la Constitución y los Tratados Internacionales de Derechos Humanos o disposiciones de orden público. De esta manera, más allá del mero análisis formal sobre la existencia de los requisitos identificados en el artículo $54 \mathrm{P}$, el tribunal a quien corresponda el análisis de los acuerdos, debería tener las facultades para analizar dichos $\operatorname{aspectos}^{51}$.

En el mismo informe, la Corte Suprema también indicó que:

no es claro si el artículo en su integridad permite que existan acuerdos colectivos sin efectos erga omnes (es decir, sólo respecto de quienes han sido efectivamente representados en el acuerdo), requiriendo para ello la sola publicación de la resolución del Servicio en los diarios y medios que la ley señala; o, si por el contrario, la aprobación judicial se requerirá en todos los casos de acuerdos colectivos, incorporándose, incluso, los acuerdos arribados en casos donde los consumidores afectados sean determinables (afectaciones colectivas) o indeterminados (afectaciones difusas), lo que hace aconsejable precisar este punto.

Tampoco queremos dejar de mencionar, en cuanto al efecto erga omnes, lo relativo al efecto concreto que produce el acuerdo. En tal sentido, el artículo $54 \mathrm{Q}$ inciso $3 .^{\circ}$ dispone que:

una vez ejecutoriada la resolución judicial que aprueba el acuerdo y efectuadas las publicaciones respectivas que indica el proyecto, el acuerdo surtirá los efectos de una transacción extrajudicial respecto de todos los consumidores potencialmente afectados, con excepción de aquéllos que hayan hecho valer sus derechos ante los tribunales con anterioridad, hayan suscrito avenimientos o transacciones de carácter individual con el proveedor, o hayan efectuado reserva de sus acciones. 
Sobre esta materia, el denominado "voto autónomo" del ministro Romero en la sentencia TC. Rol n. ${ }^{\circ}$ 4012-2017 ${ }^{52}$, ha planteado las siguientes interrogantes:

¿Se requiere que exista una conducta ya ejecutada por un proveedor para que exista el acuerdo del artículo 54 Q, o puede todavía no existir? ¿La conducta que se ordena cesar debe producir efectos vulneratorios a los derechos de los consumidores? Más importante aún, épuede el Servicio Nacional del Consumidor acordar requisitos, condiciones o la prohibición de conductas o clases de conductas que tengan como sujeto pasivo no sólo al proveedor que suscribe el acuerdo, sino que a otros proveedores, invocando el efecto "erga omnes" de la sentencia judicial que aprueba el acuerdo? ¿El incumplimiento de los requisitos, condiciones o la prohibición de conductas o clases de conductas que se aprueben judicialmente, constituirá una sanción de infracción a la ley (artículo $54 \mathrm{Q}$, inciso final) para otros proveedores, dado el efecto "erga omnes" del acuerdo?"

Vinculado a lo anterior, y en una mirada muy crítica al procedimiento establecido, se dijo, en su oportunidad, que el párrafo $5 .^{\circ}$ del Proyecto [que regula el procedimiento voluntario]

lo que hace es supeditar, de manera obligatoria, la facultad legal que tienen las asociaciones de consumidores o los consumidores afectados agrupados, de interponer acciones colectivas cuando se haya iniciado este procedimiento "voluntario" en una sede no judicial ${ }^{54}$. De tal modo que "por un procedimiento administrativo "voluntario" se restringe una facultad que la ley entrega a entes distintos del aparataje estatal, cambiando totalmente las reglas del juego de lo que siempre ha existido [...], introduciendo un elemento que desnaturaliza la misión que tiene la acción colectiva sobre siempre ser conocida por un tercero imparcial que determine el daño y reparación que debe tener cada consumidor afectado". Sin perjuicio de ello, se establece (artículo $54^{\circ} \mathrm{Q}$ ) que para que la resolución del SERNAC produzca efectos erga omnes, deberá ser aprobado por el juez de letras en lo civil correspondiente al domicilio del proveedor. En este sentido, se establece un procedimiento voluntario que debe ser aprobado en sede judicial, y, además, un procedimiento judicial ${ }^{55}$.

\section{Ventajas del "procedimiento voluntario para la protección del interés colectivo o difuso de los consumidores"}

Dentro de las ventajas del denominado "Procedimiento voluntario para la protección del interés colectivo o difuso de los consumidores", se encuentra, sin duda, la de conformar una salida más rápida, eficiente y con ahorro de recursos. El nuevo artículo $54 \mathrm{H}$ de la Ley 19.496 se encarga de aclarar que los principios que guían esta solución son los de indemnidad del consumidor, la economía procesal, la publicidad, la integridad y el debido proceso. De esta forma, la jurisdicción queda reducida a la solución de controversias que no se han podido solucionar por el procedimiento voluntario, porque éste ha fracasado ${ }^{56}$.

Otra ventaja muy importante está conformada por la apertura al diálogo y, por lo mismo, la flexibilidad ${ }^{57}$, que permite llegar a soluciones más perfectas y ajustadas a las complejidades del caso. Esto, a diferencia del amplio abanico de posibilidades aportadas por la alternativa del proceso judicial.

Asimismo, constituye una herramienta que aporta soluciones a quienes no habrían tenido mayores incentivos para buscarlas de forma individual. Sobre este punto, la modificación contenida en la Ley 21.081 permite velar también por los derechos de aquellos consumidores que no se encuentran activamente involucrados en un proceso de carácter colectivo ${ }^{58}$. En tal sentido, en forma muy acertada, se ha expresado que:

no basta con "conceder" derechos al consumidor. Es necesario establecer mecanismos adecuados para que el consumidor los

pueda "hacer valer" 59 . Es evidente que el consumidor puede ejercitar esos derechos por la vía judicial. Sin embargo, esta vía es insatisfactoria para el consumidor, por varias razones. Por una parte, los procesos judiciales no son, por lo general, adecuados para solventar controversias de escasa cuantía económica. El consumidor renunciará a la realización de su derecho cuando compruebe que son mayores los costos totales del proceso que su interés en el pleito ${ }^{60}$.

Por otro lado, también se pone de manifiesto la situación de inferioridad del consumidor respecto del empresario en este ámbito. Este último celebra contratos en masa, con la posibilidad real de prepararse anticipadamente ante cualquier reclamación, frecuentemente asesorado por abogados y con la capacidad de 
internalizar los costos de toda posible demanda para repartirlos en los precios de los productos finales. Para el consumidor, por el contrario, "la lesión de su interés tiene un carácter imprevisto, que le obliga a reaccionar con rapidez, debiendo buscar consejo en personas extrañas. En definitiva, la vía judicial es lenta y puede causar costes económicos al consumidor" ${ }^{\prime 1}$.

Finalmente, al ser el SERNAC quien interviene a favor de los consumidores, se excluye, en gran parte, la asimetría que suele caracterizar las relaciones consumidor-proveedor, lo que permite una negociación entre iguales o, por lo menos, mucho más cercana a esa idea.

\section{El intento de institucionalizar la conciliación en el ámbito del procedimiento sancionatorio}

En el ámbito del procedimiento sancionatorio en el Proyecto, incorporaba la existencia de mediación individual y conciliación en el párrafo $2^{\circ}$ de este último. Las facultades y procedimientos recién referidos, otorgados al SERNAC por el proyecto, fueron declarados inconstitucionales por el Tribunal Constitucional, en sentencia Rol 4012-2017².

En primer lugar, veremos en qué consistían dichos procedimientos y, en segundo lugar, señalaremos las razones del Tribunal Constitucional para estimarlos contrarios a la Constitución.

El artículo $50 \mathrm{G}$ del Proyecto señalaba que el procedimiento administrativo sancionatorio podría iniciarse de oficio o por denuncia. Asimismo, indicaba que las denuncias se pondrían en conocimiento del proveedor con el fin de que este propusiera alternativas concretas de solución o corrección al hecho denunciado.

En el evento de que el denunciante aceptara la propuesta, el acuerdo voluntario debería constar por escrito y tendría el valor de una transacción extrajudicial, de modo que, una vez cumplidas sus estipulaciones, se extinguirían las acciones del denunciante para perseguir la responsabilidad contravencional y civil del proveedor.

En caso de que el consumidor no aceptara la propuesta del proveedor, o si éste no propusiere alternativas de solución o corrección, tendría lugar una audiencia obligatoria de conciliación ${ }^{63}$, audiencia que tendría los caracteres de brevedad y desformalización. A ella deberían asistir consumidor y proveedor, personalmente o representados. En caso de llegar a un acuerdo, el acta debería expresar las obligaciones contraídas por el proveedor y la forma y plazo de cumplimiento de las mismas.

El acta de conciliación, debidamente certificada, tendría mérito ejecutivo y, una vez cumplidas las estipulaciones del acuerdo, se extinguirían las acciones del denunciante para perseguir la responsabilidad contravencional y civil del proveedor. Lo mismo ocurriría en el caso de los acuerdos alcanzados con las asociaciones de consumidores acreditadas que alcancen acuerdos con el proveedor en representación de los consumidores.

Las razones que esgrimió el Tribunal Constitucional para declarar inconstitucionales esos procedimientos fueron, básicamente, las contenidas en el considerando $35 .^{\circ}$ de dicha sentencia, el cual declara que:

En el Proyecto controlado, no implica solamente que el Servicio Nacional del Consumidor pueda multar a los proveedores, en paralelo con los tribunales. Se trata de que, además, se rige en instancia de mediación; arbitra a continuación una audiencia obligatoria de conciliación (artículo $50 \mathrm{G}$ ); para concluir pudiendo ordenar el cese de las conductas infractoras, la restitución de los cobros que le parezcan improcedentes, así como adoptar indeterminadas medidas para evitar supuestas infracciones futuras (artículo $50 \mathrm{~N})$... $^{64}$.

A continuación, el considerando $36 .^{\circ}$ señala:

Que todo este conjunto de antecedentes, analizados y concatenados entre sí, revelan inequívocamente que en estos casos el Servicio Nacional del Consumidor entraría a ejercer "jurisdicción” [...]. La pregunta siguiente, por ende, es si el Servicio Nacional del Consumidor puede actuar como juez, o al menos, como un órgano que ejerce jurisdicción. La respuesta, 
negativa, a su turno, exige una especial articulación de las normas constitucionales vigentes y los principios generales del derecho público chileno que rigen la materia ${ }^{65}$.

$\mathrm{Al}$ respecto, en el considerando 38. ${ }^{\circ}$ el Tribunal Constitucional ha expresado que el SERNAC no cumple los requisitos mínimos de ser un tercero independiente e imparcial y agrega que no procede que "el mismo servicio estatal llamado a proteger a una de las partes lucrativamente interesadas, los consumidores, sea instituido como árbitro supremo, para luego dirimir los contenciosos e impugnaciones que enderecen contra sus proveedores" ${ }^{66}$.

Finalmente, sobre este punto, el considerando 39. del fallo indica que "el proyecto de ley examinado no solo no dota al Servicio Nacional con reglas ecuánimes de actuación, sino que abre espacios de amplia discrecionalidad, que amagan predisponerlo en contra de los derechos de los proveedores" ${ }^{\prime 67}$.

\section{Referencias}

Ángel Avilés Herández, María Diez de Revenga Giménez \& Elena Jover Coy, La mediación. El abogado ante el proceso de mediación, Revista jurídica de la Región de Murcia, n. ${ }^{\circ}$ 48, 14-45 (2014).

Chile, Dictamen 94.206 de 2014 [Contraloría General de la República]. Aplica dictamen 71055/2013. 04-12-2014. http://www.contraloria.cl/LegisJuri/DictamenesGeneralesMunicipales.nsf/FormImpresionDict amen?OpenForm\&UNID=46361CAF8226F35C84257DAA004CC7E3

Chile, Ley 19.496, Establece normas sobre protección de los derechos de los consumidores, Diario Oficial 07 de febrero de 1997. http://bcn.cl/1uvuj

Chile, Ley 21.081, Modifica ley 19.496, sobre protección de los derechos de los consumidores, Diario Oficial 13 de julio de 2018. http://bcn.cl/26zn5

Chile, Oficio 129-2017 de 16 de agosto de 2017, Informe de la Corte Suprema de Chile al Proyecto de Ley Boletín n. ${ }^{\circ}$ 9.369-03, cuya tramitación derivó en la dictación de la Ley n. ${ }^{\circ}$ 21.081, Diario Oficial 13 de julio de 2018.

Chile, Resolución Exenta n. ${ }^{\circ} 429$, de 2016, del Ministerio de Economía, Fomento y Turismo, Servicio Nacional del Consumidor.

Chile, Tribunal Constitucional, 18 de enero de 2018, Rol 4012-2017. Cita en línea: CL/JUR/466/2018.

Claudio Fuentes Maureira, Mediación colectiva, el Proyecto de ley de fortalecimiento del SERNAC y la necesidad de tomarse los derechos 'colectivos' en serio, Instituto Chileno de Derecho Procesal (2016). http://www.ichdp.cl/mediacion-colectiva-el-proyecto-de-ley-de-fortalecimiento-del-sernac-y-la-necesi dad-de-tomarse-los-derechos-colectivos-en-serio/

Darío Parra Sepúlveda, Aníbal Olivares Vanetti \& Camila Riesco Mendoza, La mediación en el ámbito de la salud y su rol en la relación sanitaria, 89 Revista de derecho (Concepción), n. ${ }^{\circ}$ 243, 121-144 (2018). https://revistaschile nas.uchile.cl/handle/2250/72810

Directiva 2013/11/ue del parlamento europeo y del consejo de 21 de mayo de 2013, relativa a la resolución alternativa de litigios en materia de consumo y por la que se modifica el Reglamento (CE) no 2006/2004 y la Directiva 2009/22/CE. Diario Oficial de la Unión Europea L 165/63. https://eur-lex.europa.eu/legal-content/ES/TXT /?uri=CELEX\%3A32013L0011

Eduardo Jequier Lehuedé, La mediación como alternativa de solución de los conflictos empresariales en Chile. Razones y mecanismos para su regulación, 29 Revista de Derecho (Valdivia), n. ${ }^{\circ}$ 1, 91-118 (2016). https://doi.org/10.406 7/S0718-09502016000100005

Franziska Weber, Is ADR the Superior Mechanism for Consumer Contractual Disputes? - an Assessment of the Incentivizing. Effects of the ADR Directive, 38 Journal of Consumer Policy, n. 3 , 265-285 (2015). https://doi.o $\mathrm{rg} / 10.1007 / \mathrm{s} 10603-015-9291-7$

Hans-W. Micklitz \& Geneviève Saumier, Enforcement and Effectiveness of Consumer Law (Springer, 2018). https:/ /doi.org/10.1007/978-3-319-78431-1 
Hans-W. Micklitz, Jules Stuyck, Evelyne Terryn, Cases, Materials and Text on Consumer Law (D. Droshout Coor., Hart Publishing, 2010).

International Academy of Comparative Law, The Enfocement and Effectiveness of the Law, Thematic Congress (Montevideo, 2016). https://aidc-iacl.org/enforcement-and-effectiveness-of-the-law-general-contributions-of -the-montevideo-thematic-congress/Servicio Nacional del Consumidor. 4 de mayo de 2016. Solicitud de Información n. ${ }^{\circ}$ AH009T0000193.Servicio Nacional del Consumidor. 20 de enero de 2016. Solicitud de Información n. AH009T0000102.

Ma. Guadalupe Márquez Algarra \& José Carlos De Villa Cortés, Medios alternos de solución de conflictos (2013). h ttps://archivos.juridicas.unam.mx/www/bjv/libros/8/3568/15.pdf

Macarena Vargas, El Servicio Nacional del Consumidor como mediador individual o la incompatibilidad de caracteres, en Boletín Especial, Academia Derecho y Consumo, 11-14 (2017). http://derechoyconsumo.udp.cl/wp-conte nt/uploads/2017/12/Macarena-Vargas.pdf

Maite Aguirrezabal Grünstein, Intereses supraindividuales: acción colectiva, mediación colectiva, en Reformas al Sernac. Comentarios y Propuestas, Fundación Fernando Fueyo (2015). http://derechoyconsumo.udp.cl/wp-content/u ploads/2015/10/Propuestas-proyecto-de-fortalecimiento-al-Sernac.pdf

Manuel Jesús Marín López, Consumidores y medios alternativos de resolución de conflictos (2007). http://centrodeestu diosdeconsumo.com/images/ARBITRAJE/16.pdf

Marco B. M. Loos, Enforcing Consumer Rights through ADR at the Detriment of Consumer Law, 24 European Review of Private Law, n. 1, 61-79 (2016). https://pure.uva.nl/ws/files/8963817/513990.pdf

María Elisa Morales, Control by negotiating. Un estudio de Derecho Comparado, 2 Latin American Legal Studies, 67-92 (2018). https://doi.org/10.15691/0719-9112VOL2A4

María Elisa Morales Ortíz, Algunos mecanismos de control de cláusulas abusivas en el ordenamiento jurídico chileno, Revista de Derecho-Universidad Católica de la Santísima Concepción, n. 3 32, 71-91 (2016).

María Elisa Morales Ortíz, Control de cláusulas abusivas en el proyecto de ley que fortalece las facultades del SERNAC, en Boletín Especial, Academia Derecho y Consumo, 3-6 (2017). http://derechoyconsumo.udp.cl/wp-content/ uploads/2017/12/Mari\%CC\%81a-Elisa-Morales.pdf

María Fernanda Vásquez Palma (Coord.), Mecanismos alternativos de solución de conflictos (Legal PublishingThomson Reuters Chile, 2018).

Nathalie Walker, Algunos comentarios acerca de la mediación en acciones colectivas en el Proyecto de Ley n. ${ }^{\circ} 9369-03$, que modifica la Ley sobre Protección de los Derechos de los Consumidores, en Boletín Especial, Academia de Derecho y Consumo, 37-40 (2017). http://derechoyconsumo.udp.cl/wp-content/uploads/2017/12/Boleti\%CC\%81nespecial-ADECO-vf.pdf

Nathalie Walker, El SERNAC y las mediaciones colectivas. Esperando a Godot, en Estudios de Derecho del Consumidor, 125-142 (H. Carrasco ed., Rubicón, 2018).

Organización para la cooperación y el desarrollo económicos (OCDE), Recomendación de la OCDE sobre resolución de disputas y resarcimiento a consumidores. https://www.oecd.org/mexico/40060255.pdf

Pablo Rodríguez Árias, Modificación a la modificación de la Ley sobre Protección de los Derechos de los Consumidores (Mensaje $N^{o} 036-365$ de 27 de abril de 2017), El Mercurio (3 de julio, 2017). http://www.elmercurio.com/Legal/Noticias/Opinion/2017/07/03/Modificacion-a-la-modificacion-d e-la-Ley-sobre-Proteccion-de-los-Derechos-de-los-Consumidores-Mensaje-N036365-de-27-de-abril-de-2017.a $\operatorname{spx}$

Susana San Cristóbal Reales, Sistemas alternativos de resolución de conflictos: negociación, conciliación, mediación, arbitraje en el ámbito civil y mercantil, Anuario Jurídico y Económico Escurialense, n. ${ }^{\circ} 46,39-62$ (2013). https: //dialnet.unirioja.es/descarga/articulo/4182033.pdf 


\section{Notas}

* Artículo de investigación. Se enmarca en el Proyecto DFP17-0025. Se agradece a la Dirección de Investigación de la Universidad de La Frontera, Temuco, Chile.

1 Hans-W. Micklitz, Jules Stuyck, Evelyne Terryn, Cases, Materials and Text on Consumer Law, 551 (D. Droshout Coor., Hart Publishing, 2010).

2 Íd., 512.

3 Sobre la materia, en doctrina chilena, ver María Fernanda Vásquez Palma (Coord.), Mecanismos alternativos de solución de conflictos (Legal Publishing-Thomson Reuters Chile, 2018); Darío Parra Sepúlveda, Aníbal Olivares Vanetti \& Camila Riesco Mendoza, La mediación en el ámbito de la salud y su rol en la relación sanitaria, 89 Revista de derecho (Concepción), n. ${ }^{\circ}$ 243, 121-144 (2018).

4 Franziska Weber, Is ADR the Superior Mechanism for Consumer Contractual Disputes? -an Assessment of the Incentivizing. Effects of the ADR Directive, 38 Journal of Consumer Policy, n. ${ }^{\circ}$ 3, 265 (2015).

5 María Elisa Morales Ortíz, Algunos mecanismos de control de cláusulas abusivas en el ordenamiento jurídico chileno, Revista de Derecho-Universidad Católica de la Santísima Concepción, n. 32, 71-91 (2016).

6 El Ombudsman surge como una especie de mediador entre los ciudadanos y la administración del Estado, sin embargo, la figura del Consumer Ombudsman tiene facultades más amplias que las de un mediador. El Consumer Ombudsman tiene facultades para accionar antes los tribunales, para prevenir infracciones a través de negociaciones y recomendaciones, en defensa de los intereses de los consumidores. Hans-W. Micklitz, Jules Stuyck, Evelyne Terryn, op. cit.,54

7 Hans-W. Micklitz, Jules Stuyck, Evelyne Terryn, op. cit., 511.

8 Organización para la cooperación y el desarrollo económicos (OCDE), Recomendación de la OCDE sobre resolución de disputas y resarcimiento a consumidores.

9 Hans-W. Micklitz \& Geneviève Saumier, Enforcement and Effectiveness of Consumer Law, 3 y ss. (Springer, 2018).

10 International Academy of Comparative Law, The Enfocement and Effectiveness of the Law, Thematic Congress (Montevideo, 2016).

11 Directiva 2013/11/ue del parlamento europeo y del consejo de 21 de mayo de 2013, relativa a la resolución alternativa de litigios en materia de consumo y por la que se modifica el Reglamento (CE) no 2006/2004 y la Directiva 2009/22/ CE. Diario Oficial de la Unión Europea L 165/63.

12 Hans-W. Micklitz, Jules Stuyck, Evelyne Terryn, op. cit., 512.

13 Íd.

14 Marco B. M. Loos, Enforcing Consumer Rights through ADR at the Detriment of Consumer Law, 24 European Review of Private Law, n. ${ }^{\circ}$ 1, 61-79 (2016).

15 En adelante, simplemente "Proyecto" o "Proyecto de Ley".

16 Hans-W. Micklitz, Jules Stuyck, Evelyne Terryn, op. cit., 513.

17 Ángel Avilés Herández, María Diez de Revenga Giménez \& Elena Jover Coy, La mediación. El abogado ante el proceso de mediación, Revista jurídica de la Región de Murcia, n. ${ }^{\circ}$ 48, 25 (2014); Ma. Guadalupe Márquez Algarra \& José Carlos De Villa Cortés, Medios alternos de solución de conflictos (2013).

18 Ángel Avilés Herández, María Diez de Revenga Giménez \& Elena Jover Coy, op. cit., 26.

19 Chile, Dictamen 94.206 de 2014 [Contraloría General de la República]. Aplica dictamen 71055/2013. 04-12-2014.

20 En efecto, se ha dicho que: "existe lo que, hasta ahora, ha sido una práctica del SERNAC no regulada en la LPDC". María Elisa Morales Ortíz, Control de cláusulas abusivas en el proyecto de ley que fortalece las facultades del SERNAC, en Boletín Especial, Academia Derecho y Consumo, 3-6 (2017).

21 Macarena Vargas, El Servicio Nacional del Consumidor como mediador individual o la incompatibilidad de caracteres, en Boletín Especial, Academia Derecho y Consumo, 11 (2017). Para esta autora, "la mediación individual y el SERNAC serían, para estos efectos, las partes de un matrimonio mal avenido y destinado a la ruptura precisamente por incompatibilidad de caracteres".

22 Nathalie Walker, Algunos comentarios acerca de la mediación en acciones colectivas en el Proyecto de Ley $N^{\circ}$ 9369-03, que modifica la Ley sobre Protección de los Derechos de los Consumidores, en Boletín Especial, Academia de Derecho y Consumo, 37-40 (2017).

23 El hecho de no constituir una mediación ha sido reconocido por Vargas, en los siguientes términos: "La labor que en la actualidad realiza el SERNAC para resolver casos individuales no financieros y-que pretende seguir haciendo con la nueva ley- no es ni será una mediación. Lo que hace es otra cosa, mejor o peor, no sabemos, simplemente es algo muy distinto". Macarena Vargas, op. cit., 13. En un sentido similar, Nathalie Walker, El SERNAC y las mediaciones colectivas. Esperando a Godot, en Estudios de Derecho del Consumidor, 125-142 (H. Carrasco ed., Rubicón, 2018). A propósito del control de cláusulas abusivas, ver María Elisa Morales, Control by negotiating. Un estudio de Derecho Comparado, 2 Latin American Legal Studies, 67-92 (2018). 
29 Chile, Resolución Exenta 429 de 2016 [Servicio Nacional del Consumidor].

30 Servicio Nacional del Consumidor. 4 de mayo de 2016. Solicitud de Información n. AH009T0000193.

31 Chile, Proyecto de Ley Boletín n. ${ }^{\circ}$ 9369-03, ingresado a tramitación legislativa el 03 de junio de 2014 y que derivó en la dictación de la Ley n. ${ }^{\circ} 21.081$, Diario Oficial 13 de julio de 2018.

32 Macarena Vargas, op. cit., 13.

33 Chile, Tribunal Constitucional, 18 de enero de 2018, Rol 4012-2017. Cita en línea: CL/JUR/466/2018.

34 El art. 1, n. ${ }^{\circ}$ 3, letra h) de la Ley 21.081 modifica el art. 8 de la Ley 19496, al incorporar al texto una letra h) que otorga a las asociaciones de consumidores la función de: "h) Realizar, a solicitud de un consumidor, mediaciones individuales".

35 Denominadas así por la práctica del SERNAC. Como ya se dijo, técnicamente no son mediaciones ya que no se verifica la figura triangular con un tercero imparcial entre las partes. Para nosotros es más una negociación. Otra apreciación crítica sostiene que sería más propio hablar de "conciliación colectiva". Ver Maite Aguirrezabal Grünstein, Intereses supraindividuales: acción colectiva, mediación colectiva, en Reformas al Sernac. Comentarios y Propuestas, Fundación Fernando Fueyo (2015).

36 Chile, Dictamen 94.206 de 2014 [Contraloría General de la República]. Aplica dictamen 71055/2013. 04-12-2014.

37 Véase, para estos efectos, la página: https://www.sernac.cl/proteccion-al-consumidor/mediaciones-colectivas/

38 Servicio Nacional del Consumidor. 20 de enero de 2016. Solicitud de Información n. ${ }^{\circ}$ AH009T0000102.

39 Íd.

40 Íd.

41 Íd.

42 Nathalie Walker, Algunos comentarios acerca de la mediación en acciones colectivas en el Proyecto de Ley n. ${ }^{\circ}$ 9369-03, op. cit., 37.

43 Chile, Ley 21.081, Modifica ley 19.496, sobre protección de los derechos de los consumidores, Diario Oficial 13 de julio de 2018.

44 Pablo Rodríguez Árias, Modificación a la modificación de la Ley sobre Protección de los Derechos de los Consumidores (Mensaje $N^{\circ} 036-365$ de 27 de abril de 2017), El Mercurio (3 de julio, 2017).

45 En su prevención al voto de mayoría, el ministro Romero lo consideró incompatible con al art. 19 No3 inciso sexto de la Constitución, por cuanto: "la falta de determinación de la expresión 'erga omnes' del artículo 54 Q, sumado a la aplicación del artículo $54 \mathrm{P}$, inciso segundo, numeral primero, introduce un grado de especificidad legal en un acuerdo con efectos potencialmente normativos o sancionatorios". Chile, Tribunal Constitucional, 18 de enero de 2018, Rol 4012-2017, 60. Cita en línea: CL/JUR/466/2018. Por su parte, la ministra Peña estuvo en contra de la declaración de ley orgánica constitucional del art. $1^{\circ} \mathrm{N} \times 45$, "que agrega un nuevo artículo 54 Q a la Ley n. ${ }^{\circ} 19.496$, con excepción de su inciso primero, por incidir también en materias de procedimiento que no son propias de la organización y atribuciones de los tribunales de justicia" Chile, Tribunal Constitucional, 18 de enero de 2018, Rol 4012-2017, 68. Cita en línea: CL/JUR/466/2018.

46 Íd., 15.

47 Íd., 59. El voto disidente del ministro Romero apunta que habría un problema de constitucionalidad "en la falta de determinación del efecto erga omnes en relación al primer numeral del art. 54 P”.

48 Chile, Ley 21.081, Modifica ley 19.496, sobre protección de los derechos de los consumidores, Diario Oficial 13 de julio de 2018.

49 También se refiere al contenido del informe de la Corte Suprema el considerando 52 de la prevención del ministro Romero. Chile, Tribunal Constitucional, 18 de enero de 2018, Rol 4012-2017, p. 59. Cita en línea: CL/JUR/466/2018.

50 Chile, Ley 21.081, Modifica ley 19.496, sobre protección de los derechos de los consumidores, Diario Oficial 13 de julio de 2018.

51 Chile, Oficio 129-2017 de 16 de agosto de 2017, Informe de la Corte Suprema de Chile al Proyecto de Ley Boletín n. ${ }^{\circ}$ 9.369-03, cuya tramitación derivó en la dictación de la Ley n. ${ }^{\circ}$ 21.081, Diario Oficial 13 de julio de 2018.

52 Chile, Tribunal Constitucional, 18 de enero de 2018, Rol 4012-2017. Cita en línea: CL/JUR/466/2018.

53 Íd., 60.

54 Pablo Rodríguez Árias, op. cit. 
55 Pablo Rodríguez Árias, op. cit.

56 Nótese que, pese a haber sido considerado este artículo como materia de ley orgánica constitucional, la parte vinculada a los principios básicos que informan al procedimiento voluntario no deja de tener sentido y aplicabilidad. Susana San Cristóbal Reales, op. cit., 41 .

57 María Elisa Morales Ortíz, Control de cláusulas abusivas en el proyecto de ley que fortalece las facultades del SERNAC, en Boletín Especial, Academia Derecho y Consumo, 3-6 (2017).

58 Claudio Fuentes Maureira, Mediación colectiva, el Proyecto de ley de fortalecimiento del SERNACy la necesidad de tomarse los derechos 'colectivos' en serio, Instituto Chileno de Derecho Procesal (2016).

59 En esta materia se ha dicho, con gran acierto, que existen dos factores indispensables para el buen funcionamiento del sistema: "la necesaria suspensión de los plazos de prescripción y caducidad, por todo el tiempo que dure el procedimiento [...] y la ejecutividad que se le asigna al título en que consta el acuerdo [..., dependiendo si éste se logró antes o durante el proceso judicial o arbitral, y dentro o fuera del país" Eduardo Jequier Lehuedé, La mediación como alternativa de solución de los conflictos empresariales en Chile. Razones y mecanismos para su regulación, 29 Revista de Derecho (Valdivia), n. ${ }^{\circ}$ 1,105 (2016).

60 Manuel Jesús Marín López, Consumidores y medios alternativos de resolución de conflictos (2007).

61 Íd.

62 Íd.

63 En cuanto a la diferencia fundamental entre los procedimientos de mediación y conciliación, se ha expresado que: "La mediación y la conciliación son autocompositivas, porque si bien interviene un tercero, éste no tiene ningún poder de decisión sobre las partes, la cuales son las únicas que tienen la facultad de decidir si llegan no a un acuerdo de voluntades que ponga fin a su conflicto de intereses [...]”. La gran diferencia entre estos dos mecanismos radica en los límites de la intervención del tercero ajeno al conflicto, ya que mientras el mediador únicamente puede ayudar a facilitar la comunicación entre las partes para que lleguen a un acuerdo que ponga "fin a su conflicto de intereses, el conciliador, además, puede proponer posibles soluciones al conflicto” Ma. Guadalupe Márquez Algarra Y \& José Carlos De Villa Cortés, op. cit., 1588. (2013). 1588. (2013).

64 Chile, Tribunal Constitucional, 18 de enero de 2018, Rol 4012-2017. Cita en línea: CL/JUR/466/2018.

65 Íd.

66 Chile, Tribunal Constitucional, 18 de enero de 2018, Rol 4012-2017. Cita en línea: CL/JUR/466/2018.

67 Íd.

\section{Licencia Creative Commons CC BY 4.0}

Cómo citar este artículo: María Elisa Morales \& Nathalie Walker, Resolución alternativa de conflictos ante el Servicio Nacional del Consumidor, 69 Vniversitas (2020). https://doi.org/10.11144/Javeriana.vj69.racs 